\title{
Micro channel and heat transfer column structure effect on heat dissipation performance of LTCC microwave component by numerical simulation analysis
}

\author{
Zhiping Liao $^{1, a}$ \\ School of Mechanical and Electrical Engineering \\ Guilin University of Electronic Technology \\ Guilin, 541004, China \\ a122320006@qq.com
}

\author{
Zhaohua $\mathrm{Wu}^{1, \mathrm{~b}}$ \\ School of Mechanical and Electrical Engineering \\ Guilin University of Electronic Technology \\ Guilin, 541004, China \\ bemezdj@guet.edu.cn
}

\begin{abstract}
Micro channel and heat transfer column of low temperature co-fired ceramic (LTCC) microwave component, its structural parameters will affect the heat transfer performance of high heat flux microwave module. To obtain the better thermal performance of micro channel and heat transfer column structure, a three-dimensional model of LTCC microwave component is established by the finite element software ANSYS. The heat dissipation performance of component was studied by numerical simulation. Research results show the influence of the heat transfer column diameter on the heat dissipation performance of component is the biggest, the second biggest is micro channel section width. When choosing the heat transfer column diameter of $0.3 \mathrm{~mm}$, micro channel section width of $1 \mathrm{~mm}$, heat transfer column height of $0.3 \mathrm{~mm}$, micro channel section height of $0.3 \mathrm{~mm}$, the heat dissipation effect is the best, and the maximum temperature of the power chip is $43.64^{\circ} \mathrm{C}$, which can meet the requirements of the heat sink design of LTCC microwave components.
\end{abstract}

Keywords-LTCC, micro channel, heat transfer column, heat dissipation performance

\section{INTRODUCTION}

With the electronic package to process the size miniaturization, functional integration and the rapid development of high speed, the power density of the part of the high performance of the system on a single chip is expected to will be higher than $100 \mathrm{~W} / \mathrm{cm}^{2}$, such as high integration degree of LTCC microwave components [1]. Due to the high integration, the space of the heat sink is very small. Therefore, how to solve the heat dissipation of LTCC microwave components is an urgent problem [2]. Conventional air cooling method for today's high integration, high power consumption system, low thermal conductivity and low density of air convection lack of attractive [3]. The micro channel heat sink cooling method proposed by American scholar Tuckerman and Pease [4] has been paid more and more attention to solve the high heat flux microelectronic. Using micro channel and the heat transfer column structure strengthen heat dissipation of LTCC microwave components have good heat dissipation characteristics, dense, good high frequency performance, thermal expansion coefficient match with silicon, can be embedded passive components and other excellent characteristics. And it can achieve a highly integrated system as well as effectively solve the heat dissipation problem of microwave components [5]. However, there are few studies on the micro channel and heat transfer column structure model of the LTCC microwave module. In this paper, the finite element numerical simulation analysis method is used, and through the finite element software ANASYS established the threedimensional model of LTCC microwave components. Effect of rectangular micro channel and heat transfer column structure on the heat dissipation performance for LTCC microwave components is analyzed. It has guiding significance to the design of LTCC microwave module heat sink structure.

\section{HEAT-FLUID COUPLING ANALYSIS}

In this paper, the size range of the micro channel and heat transfer column structure for the LTCC microwave components is a typical micro/nano fluid dynamics problem. When the analysis is conducted, the micro scale effect is analyzed. In the micro/nano scales, the macroscopic fluid dynamics have been ignored by some force will play to a role, including the surface tension of the liquid, molecular polarizability of van der Waals force, these forces belong to the short-range force $(<1 \mathrm{~nm})$. The accumulation effect of these forces can only reach $1 \mu \mathrm{m}$ long range, far less than the micro channel size range in the paper, so three basic factors of the macroscopic fluid dynamics still applies. which are the continuity equation, the momentum conservation equation, and the energy conservation equation [6].

\section{SIMULATION MODEL}

In this paper, the LTCC microwave component is made of 20 LTCC green ceramic tapes, which single layer thickness is $0.127 \mathrm{~mm}$. The thickness of the whole component is $2.54 \mathrm{~mm}$, the length and width are $20 \times 20 \mathrm{~mm}$, as shown in Figure 1. The component contains micro channel and heat transfer column, and the micro channel section is a rectangular structure, the heat transfer column is a cylindrical structure, as shown in Figure 2. Due to the symmetry of component and save the simulation calculation time, the one micro channel model of the whole model is built at last. 


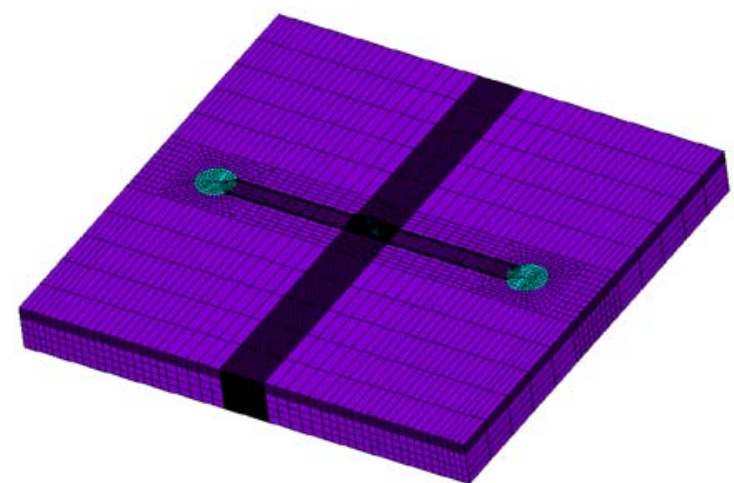

Fig. 1 The whole simulation Model

\section{SiMULATION ANALYSIS}

\section{A. Simulation analysis for heat dissipation performance in component}

In this paper, the research object of micro channel and heat transfer column structure are under the service conditions. The fluid flow is steady and incompressible laminar flow. The fluid from the inlet enter into the micro channel, and the fluid discharge is $0.5 \mathrm{~L} / \mathrm{min}$. The fluid temperature of inlet is room temperature, $25^{\circ} \mathrm{C}$. The outlet pressure of the fluid is 0 . In this paper, the heating power density of high power chip is 60 $\mathrm{W} / \mathrm{cm} 2$. The temperature distribution of the fluid in the micro channel and heat transfer column is obtained through the ANSYS heat-fluid coupling simulation analysis, as shown in

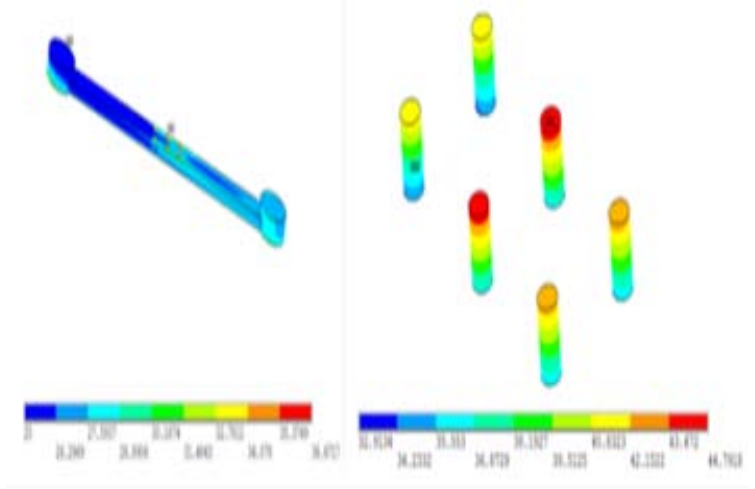

Fig. 3 Fluid and column temperature distribution

\section{B. Orthogonal experiment to optimize the micro channel and heat transfer column structure}

In this paper, we mainly study the influence of the length and width of micro channel section, heat transfer column diameter and heat transfer column height on the heat dissipation performance of the component. The micro channel section width takes $1 \sim 1.6 \mathrm{~mm}$, the Micro channel section height takes $0.3 \sim 0.9 \mathrm{~mm}$, the heat transfer column diameter takes $0.15 \sim 0.3 \mathrm{~mm}$, and the heat transfer column height takes $0.3 \sim 0.9 \mathrm{~mm}$. L16 $\left(4^{4}\right)$ orthogonal test was designed, and the finite element numerical simulation analysis was carried out on 16 sets of experiments. The maximum temperature test results

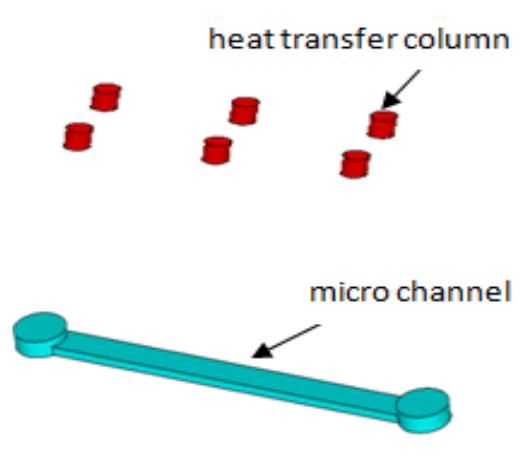

Fig. 2 Micro channel and heat transfer column structure

Figure 3. From the figure can be seen the highest temperature distribution of the fluid in the micro channel is the place connected to the heat transfer column. As the bridge between the power chip and the micro channel, the highest temperature distribution of the heat transfer column is the place connected to the power chip, and the lowest is the place connected to the micro channel. This is because the power chip is a heat source, the temperature is high, and the lower contacts with the micro channel, so the temperature is low. Figure 4 shows the overall temperature distribution and the chip temperature distribution. As can be seen from Figure 4, the around temperature of the micro channel is the lowest, and the temperature of different areas on a chip follows the location of the heat transfer column and the flow of the fluid gradually increased.

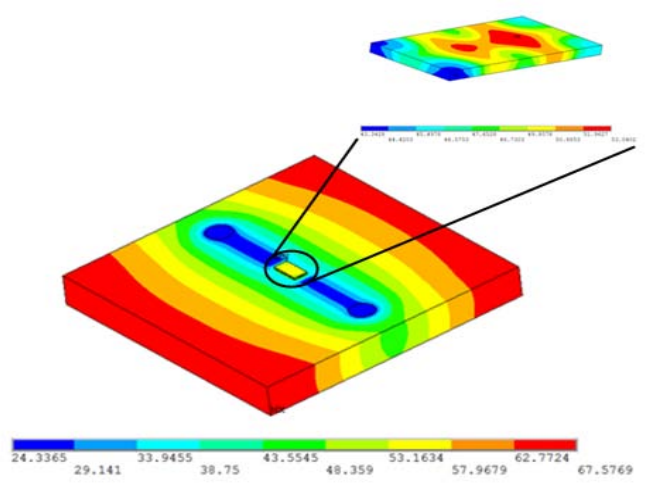

Fig. 4 Total temperature distribution of module

of the power chip were extracted respectively, as shown in Table 1.

From table 1 the range analysis, it can be seen that, among micro channel and heat transfer column structure parameters, the range values from big to small are: heat transfer column diameter $>$ Micro channel section width $>$ heat transfer column height>the Micro channel section height. The larger the range value, the larger the range value, the greater the influence of the structural factors on the heat dissipation performance of component. The relationship between the structure parameters and the heat sink performance of module is shown in Figure 5. 
TABLE I.

Simulation RESUlts of ORTHOgONAL TEST

\begin{tabular}{cccccc}
\hline Number & $\begin{array}{c}\text { Heat transfer } \\
\text { column diameter } \\
(\mathrm{mm})\end{array}$ & $\begin{array}{c}\text { Heat transfer } \\
\text { column height } \\
(\mathrm{mm})\end{array}$ & $\begin{array}{c}\text { Micro channel } \\
\text { section width } \\
(\mathrm{mm})\end{array}$ & $\begin{array}{c}\text { Micro channel } \\
\text { section height } \\
(\mathrm{mm})\end{array}$ & $\begin{array}{c}\text { Chip } \\
\text { temperature } \\
\left({ }^{\circ} \mathrm{C}\right)\end{array}$ \\
\hline 1 & 0.15 & 0.3 & 1 & 0.3 & 56.89 \\
2 & 0.15 & 0.5 & 1.2 & 0.5 & 69.67 \\
3 & 0.15 & 0.7 & 1.4 & 0.7 & 83.03 \\
4 & 0.15 & 0.9 & 1.6 & 0.9 & 98.27 \\
5 & 0.2 & 0.3 & 1.2 & 0.7 & 57.38 \\
6 & 0.2 & 0.5 & 1 & 0.9 & 61.89 \\
7 & 0.2 & 0.7 & 1.6 & 0.3 & 72.72 \\
8 & 0.2 & 0.9 & 1.4 & 0.5 & 73.89 \\
9 & 0.25 & 0.3 & 1.4 & 0.9 & 59.28 \\
10 & 0.25 & 0.5 & 1.6 & 0.7 & 64.68 \\
11 & 0.25 & 0.7 & 1 & 0.5 & 54.49 \\
12 & 0.25 & 0.9 & 1.2 & 0.3 & 58.24 \\
13 & 0.3 & 0.3 & 1.6 & 0.5 & 53.97 \\
14 & 0.3 & 0.5 & 1.4 & 0.3 & 50.52 \\
15 & 0.3 & 0.7 & 1.2 & 0.9 & 56.87 \\
16 & 0.3 & 0.9 & 1 & 0.7 & $/$ \\
K1 & 76.97 & 56.88 & 56.58 & 59.59 & $/$ \\
K2 & 66.47 & 61.69 & 60.54 & 63.00 & $/$ \\
K3 & 59.17 & 66.78 & 66.68 & 64.53 & $/$ \\
K4 & 53.60 & 70.86 & 72.41 & 69.08 & $/$ \\
R & 23.36 & 13.98 & 15.83 & 9.48 & \\
\hline
\end{tabular}

Note: in Table $1, \mathrm{Kn}$ is the average temperature of the level $\mathrm{n}$ factor; $\mathrm{R}$ is the range.

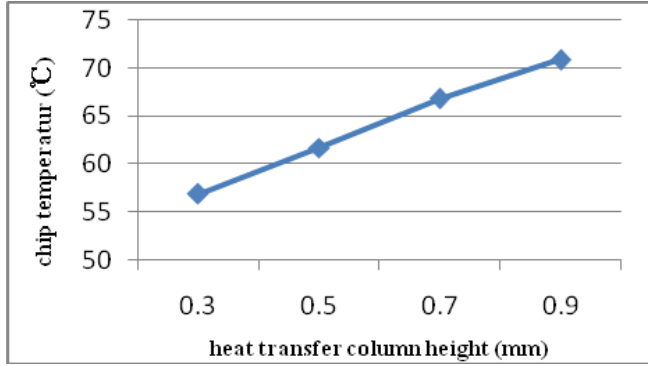

(a) Column height VS Chip temperature

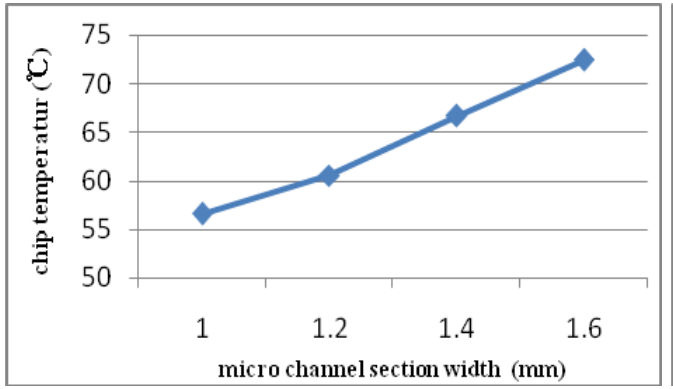

(c) Micro channel width VS Chip temperature

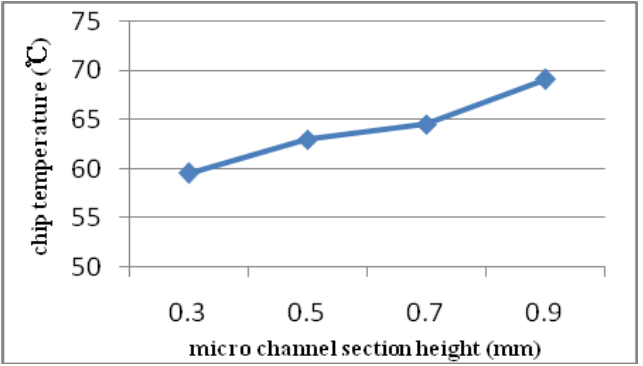

(b) Micro channel height VS Chip temperature

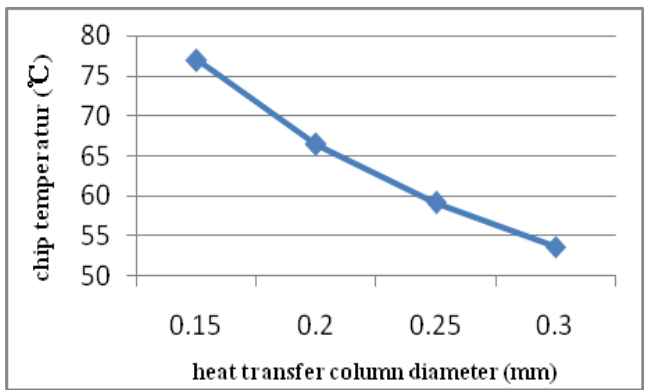

(d) Column diameter VS Chip temperature

Fig. 5 Micro channel and heat transfer column structure parameters VS Chip temperature

From Figure 5 (a) it can be seen, with the increase of heat transfer column height, the chip temperature is also increased, and the heat dissipation effect of the component becomes worse. From (b) it can be seen, the bigger of micro channel section height, the chip temperature is higher, and the increase of the amplitude is larger. As can be seen from (c), micro channel section width has little effect on the heat dissipation performance of the component. As can be seen from (d), the 
chip temperature decreases with the increase of column diameter, and the chip temperature is too high when the heat transfer column diameter is less than $0.15 \mathrm{~mm}$, the reliability of the device is reduced.

\section{MiCRO CHANNEL AND HEAT TRANSFER COLUMN}

\section{STRUCTURE PARAMETER OPTIMIZATION}

Based on the above analysis, through the orthogonal test analysis obtained optimal micro channel and the heat transfer column structure parameters combination: heat transfer column diameter is for $0.3 \mathrm{~mm}$, micro channel section width is for $1 \mathrm{~mm}$, heat transfer column height is for $0.3 \mathrm{~mm}$, micro channel section height is for $0.3 \mathrm{~mm}$. According to the combination of the optimal micro channel and heat transfer column structure parameters, the LTCC microwave component is simulated and verified, as shown in Figure 6.

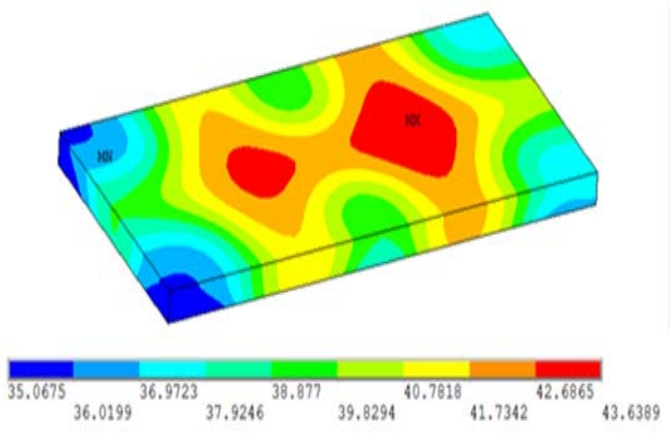

Fig. 6 Temperature distribution of the chip

From Figure 6 we can see the power chip temperature is $43.64^{\circ} \mathrm{C}$ after optimization of micro channel and heat transfer column structure. Compared with other experimental combinations, the temperature has been greatly reduced. It is showed that the optimized micro channel and heat transfer column structure can significantly improve the heat dissipation performance of the LTCC microwave component.

\section{CONCLUSIONS}

In this paper, using ANSYS finite element simulation software to study the heat dissipation performance of the micro channel and the heat transfer column structure parameters in a
LTCC microwave component, and the following important conclusions are obtained:

(1) From the orthogonal test of the simulation results can be obtained that the maximum temperature of the power chip is $98.27^{\circ} \mathrm{C}$, the minimum temperature is $50.52^{\circ} \mathrm{C}$, the average temperature is $64.05^{\circ} \mathrm{C}$. Therefore, it is known that the micro channel and the heat transfer column structure heat dissipation effect is very effective.

(2)In the micro channel and the heat transfer column structure parameters, the influence of the heat transfer column diameter on the heat dissipation performance of LTCC microwave components is the biggest, and the second is the micro channel cross section width, the smallest is the micro channel section height.

(3) Selection of the structure parameters combination of the heat transfer column diameter $0.3 \mathrm{~mm}$, micro channel crosssection width $1 \mathrm{~mm}$, heat transfer column height $0.3 \mathrm{~mm}$, micro channel section height $0.3 \mathrm{~mm}$, the heat dissipation effect is the best. The maximum temperature of the power chip is $43.64 \mathrm{C}$, which can meet the requirements of the heat sink design of LTCC microwave components.

\section{Acknowledgment}

This work was supported by advanced research project “The Study of *** Multi-energy***” .

\section{References}

[1] K. Malecha, L.J. Golonka. Three-dimensional structure of zeroshrinkage LTCC ceramics for micro fluidic applications[J]. Microelectron Reliable, 2009, 49: 585-591.

[2] Thelemann, T. et al, Liquid Cooled LTCC-Substrates for High Power Applications, Int J Microcircuits ElectronPackag, Vol. 23, No.2 (2000), pp. 209-214.

[3] Liu Shutian, Zhang Yongcun, Liu Peng. Heat Transfer and Pressure Drop in Fractal Microchannel Heat Sink for Cooling of Electronic Chips[J]. Heat Mass Transfer,2007,44:221-227.

[4] D.B. Tuckerman, R.F.W. Pease. High-performance heat sinking for VLSI[J]. IEEE Electron Device Letters, 1981, 2(5): 126-129.

[5] Y. Zhang, W. Wang, L. Tian, X.W. Liu and L. Li: Micro-Nano Electronic Technology[J], Vol. 1 (2008) No.45, p.33.

[6] Navin Raja Kuppusamy, R. Saidur, N. N. N. Ghazali, H. A. Mohammed, Numerical study of thermal enhancement in micro channel heat sink with secondary flow, International Journal of Heat and Mass Transfer[J], 2014(78):216-223. 